\title{
Prescreening for European Prevention of Alzheimer Dementia (EPAD) trial-ready cohort: impact of $A D$ risk factors and recruitment settings
}

Lisa Vermunt ${ }^{1 *}$ D, Graciela Muniz-Terrera², Lea ter Meulen ${ }^{1}$, Colin Veal ${ }^{3}$, Kaj Blennow ${ }^{4,5}$, Archie Campbell $^{6}$, Isabelle Carrié ${ }^{7}$, Julien Delrieu ${ }^{8}$, Karine Fauria ${ }^{9}$, Gema Huesa Rodríguez ${ }^{9}$, Silvia Ingala ${ }^{10}$, Natalie Jenkins ${ }^{2}$, José Luis Molinuevo ${ }^{9}$, Pierre-Jean Ousset ${ }^{7}$, David Porteous ${ }^{6}$, Niels D. Prins ${ }^{1,11}$, Alina Solomon ${ }^{12,13}$, Brian D. Tom ${ }^{14}$, Henrik Zetterberg 4,5,15,16, Marissa Zwan ${ }^{1}$, Craig W. Ritchie ${ }^{2}$, Philip Scheltens ${ }^{1}$, Gerald Luscan ${ }^{17}$, Anthony J. Brookes ${ }^{3}$, Pieter Jelle Visser ${ }^{1,18}$ and for the IMI-EPAD collaborators

\begin{abstract}
Background: Recruitment is often a bottleneck in secondary prevention trials in Alzheimer disease (AD). Furthermore, screen-failure rates in these trials are typically high due to relatively low prevalence of AD pathology in individuals without dementia, especially among cognitively unimpaired. Prescreening on AD risk factors may facilitate recruitment, but the efficiency will depend on how these factors link to participation rates and AD pathology. We investigated whether common AD-related factors predict trial-ready cohort participation and amyloid status across different prescreen settings.
\end{abstract}

Methods: We monitored the prescreening in four cohorts linked to the European Prevention of Alzheimer Dementia (EPAD) Registry ( $n=16,877$; mean \pm SD age $=64 \pm 8$ years). These included a clinical cohort, a research inperson cohort, a research online cohort, and a population-based cohort. Individuals were asked to participate in the EPAD longitudinal cohort study (EPAD-LCS), which serves as a trial-ready cohort for secondary prevention trials. Amyloid positivity was measured in cerebrospinal fluid as part of the EPAD-LCS assessment. We calculated participation rates and numbers needed to prescreen (NNPS) per participant that was amyloid-positive. We tested if age, sex, education level, APOE status, family history for dementia, memory complaints or memory scores, previously collected in these cohorts, could predict participation and amyloid status.

Results: A total of 2595 participants were contacted for participation in the EPAD-LCS. Participation rates varied by setting between 3 and 59\%. The NNPS were 6.9 (clinical cohort), 7.5 (research in-person cohort), 8.4 (research online cohort), and 88.5 (population-based cohort). Participation in the EPAD-LCS $(n=413(16 \%))$ was associated with lower age (odds ratio $(\mathrm{OR})$ age $=0.97$ [0.95-0.99]), high education (OR $=1.64$ [1.23-2.17]), male sex (OR $=1.56[1.19-$ 2.04]), and positive family history of dementia (OR $=1.66$ [1.19-2.31]). Among participants in the EPAD-LCS, amyloid positivity (33\%) was associated with higher age $(\mathrm{OR}=1.06[1.02-1.10])$ and $A P O E \varepsilon 4$ allele carriership $(\mathrm{OR}=2.99$ [1.81-4.94]). These results were similar across prescreen settings.

(Continued on next page)

\footnotetext{
* Correspondence: I.vermunt@amsterdamumc.nl

'Department of Neurology, Alzheimer Center Amsterdam, Amsterdam

Neuroscience, Amsterdam UMC, Vrije Universiteit, PO Box 7057, 1007 MB

Amsterdam, The Netherlands

Full list of author information is available at the end of the article
}

(c) The Author(s). 2020 Open Access This article is distributed under the terms of the Creative Commons Attribution 4.0 International License (http://creativecommons.org/licenses/by/4.0/), which permits unrestricted use, distribution, and reproduction in any medium, provided you give appropriate credit to the original author(s) and the source, provide a link to the Creative Commons license, and indicate if changes were made. The Creative Commons Public Domain Dedication waiver (http://creativecommons.org/publicdomain/zero/1.0/) applies to the data made available in this article, unless otherwise stated. 


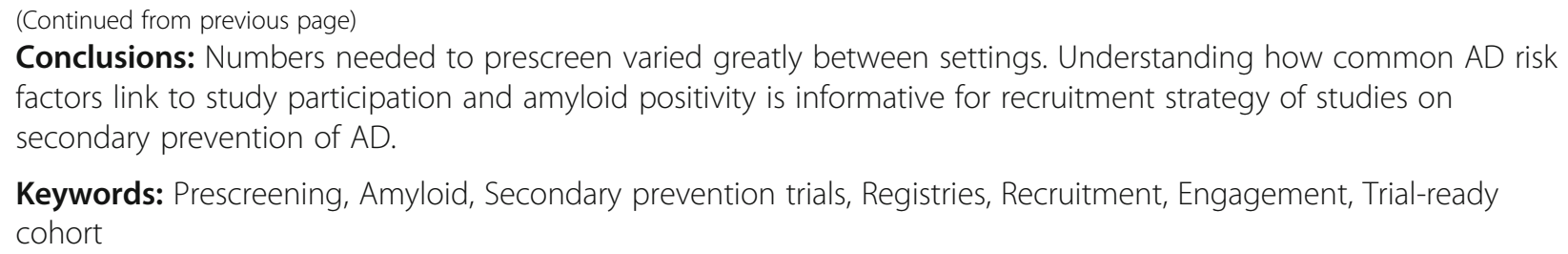

\section{Background}

Recruitment of participants for secondary prevention trials in Alzheimer disease (AD) is challenging, which can cause substantial delays in study completion [1,2]. The target population for these types of clinical trials typically comprises of individuals without signs of dementia, and with evidence of amyloid pathology [3]. Clinical trial screening of these mildly symptomatic or asymptomatic participants is accompanied by large numbers of screen failures [1]. The solution may be to introduce low-burden prescreening steps, which would limit the screening efforts to individuals with an increased prospect of enrolment into the study [4-7]. However, there is little empirical evidence on prescreening for secondary prevention trials and whether the efficacy depends on recruitment setting [8-11].

The European Prevention of Alzheimer Dementia (EPAD) Registry was set up as a virtual registry from existing cohorts [12]. The purpose was to enable recruitment and preselection of individuals for participation in the EPAD longitudinal cohort study (EPAD-LCS) [13], which also serves as a trialready cohort for the EPAD secondary prevention trials [14]. Data on several AD-related factors were available in these existing cohorts, including age, sex, education, $A P O E$ genotype, family history of dementia, subjective cognitive decline (SCD), and memory tests, as well as on common exclusion criteria. Furthermore, unlike in most trials, where a participant contacts a site following advertisements, in EPAD, researchers invited participants from the cohorts in the EPAD Registry into the EPAD-LCS. This approach allowed for investigation of how $A D$ risk factors related to the participation rate, an important consideration for the feasibility assessment of recruitment strategies. The recruitment settings linked to the registry include memory clinics, online and in-person brain research cohorts, and population-based cohorts, thereby offering the opportunity to compare them. We assessed participation rates across different recruitment settings and provide a number needed to prescreen (NNPS) to identify one eligible and amyloid-positive individual. We also tested the $\mathrm{AD}$-related factors as predictors for participation in the EPAD-LCS and for amyloid positivity.

\section{Methods}

\section{Population}

The analysis included participants from the first four cohorts that were linked to the EPAD Registry. The French
Trial Registry in Toulouse selected patients referred by GPs and self-referral from memory clinics [15]. Inclusion criteria were as follows: interest in clinical trials, available study partner, and no obvious exclusion criteria for clinical trials. Data from 195 participants without dementia, with visits between July 2016 and February 2018, had been linked to the EPAD Registry. The ALFA Study included cognitively unimpaired individuals who expressed interest in participating in $\mathrm{AD}$ research and data of 2595 participants aged over 50 years, with first visits in 2013 and 2014, were linked to the EPAD Registry [16]. Generation Scotland (GS) was a populationbased study which collected data between 2006 and 2011 in Scotland on randomly drawn individuals with a relative to co-enrol [17]. Its aim was to create a resource of human biological samples and information for medical research, and data on 13,681 participants aged over 50 years, without a known diagnosis of dementia, were linked to the EPAD Registry. The pilot 'hersenonderzoek.nl' (pilotHO.nl) was a web-based registry with the aim of recruiting people from the general public for brain research and ran from Sept 2016 to Sept 2017 when the final version of the registry was launched. This pilot registry had 412 participants, age over 50 years and without a self-reported diagnosis of dementia, linked to the EPAD Registry.

\section{EPAD Registry selection and prescreening process}

The enrolment process for the EPAD-LCS consisted of four steps. In step 1, participants were preselected from the four cohorts using algorithms in the EPAD Registry online tool [18], based on different combinations of age, sex, diagnosis of mild cognitive impairment (MCI), $A P O E$ genotype, $\mathrm{SCD}$, memory test scores, and/or family history for dementia, available in the parent cohort (Table 1). Flexible algorithms were tailored to each of the cohorts, and adjusted if the number of individuals meeting the algorithmic criteria was low. The algorithms selected individuals older than 50 years across an AD dementia risk spectrum [13]. These included those with low and medium risk for $\mathrm{AD}$ to reach the recruitment targets for the study, as well as to avoid AD risk status disclosure by invitation. In step 2, the cohorts' investigators checked eligibility of selected individuals, using data from their databases. These criteria included the EPAD 
Table 1 Baseline available data and characteristics of cohorts

\begin{tabular}{|c|c|c|c|c|}
\hline & $\begin{array}{l}\text { Toulouse } \\
\text { Registry }\end{array}$ & ALFA & $\begin{array}{l}\text { Generation } \\
\text { Scotland }\end{array}$ & pilotHO.nl \\
\hline Setting & Memory clinic & $\begin{array}{l}\text { In-person } \\
\text { research cohort }\end{array}$ & $\begin{array}{l}\text { Population- } \\
\text { based }\end{array}$ & Online research cohort \\
\hline$N$ & 195 & 2589 & 13,681 & 412 \\
\hline Age, year & $68(7)$ & $60(6)$ & $64(9)$ & $65(9)$ \\
\hline Male, $n(\%)$ & $56(29 \%)$ & $962(37 \%)$ & $5399(39 \%)$ & $155(38 \%)$ \\
\hline Highly educated, $n(\%)(n=15,239)^{*}$ & $97(60 \%)$ & 1225 (47\%) & $4860(40 \%)$ & $313(77 \%)$ \\
\hline APOE $\varepsilon 4$ genotype, $n(\%)(n=16,185)$ & NA & $872(34 \%)$ & $3695(28 \%)$ & $84(31 \%)$ \\
\hline Family history for dementia, $n(\%)(n=16,844)$ & $131(71 \%)$ & $2470(95 \%)$ & $1386(10 \%)$ & $193(50 \%)$ \\
\hline Subjective cognitive decline, $n(\%)(n=3175)^{\wedge}$ & $151(83 \%)$ & $312(12 \%)$ & NA & $81(20 \%)$ \\
\hline$\%$ low memory, $n(\%)(n=16,420)^{\$}$ & $17(15 \%)$ & $242(9 \%)$ & $1684(12 \%)$ & $20(9 \%)$ \\
\hline Diagnosed with $\mathrm{MCl}, n(\%)^{\#}$ & $13(7 \%)$ & 0 & $3(0 \%)$ & $4(1 \%)$ \\
\hline $\begin{array}{l}\text { Estimated amyloid-positive individuals based on [4], taking into account } \\
\text { age-bins, } n(\%)^{\&}\end{array}$ & 40 (22\%) & 430 (17\%) & $\sim 2680(20 \%)$ & $\sim 80(20 \%)$ \\
\hline
\end{tabular}

Legend: ${ }^{*}$ high education: Toulouse Registry: > = 14 years; ALFA Study: > = 14 years; GS: > = 14 years; pilotHO.nl: > = 6 on the Verhage scale. ^SCD: Toulouse Registry: physician diagnosis and $\mathrm{MCl}$ patients excluded; ALFA Study: memory complaints question; pilotHO.nl: questions on memory complaints with worries; \$Low memory delayed recall $z$-score <-1.28: Toulouse Registry: FCSRT delayed recall, normalised by formula (score-11)/2, at raw score cut-off < 9; ALFA Study: memory binding test, normalised to sample, at raw score cut-off < 18; GS: Wechsler logical memory - delayed recall was normalised, at raw score cut-off < 9 ; pilotHO.nl: online Muistikko-test, normalised to sample, at raw score cut-off < 9. ${ }^{*} \mathrm{MCl}$ : Toulouse Registry: physician diagnosis; pilotHO.nl and Generation Scotland self-report. In the ALFA study no $\mathrm{MCl}$ patients were enrolled. ${ }^{\&}$ Formula based on Janssen et al. [4] ( $N$ age bin 50 to 57.5 years) $\times 12.9 \%+(N$ age bin 57.5 to 62.5 years $) \times 15.8 \%+(N$ age bin 62.5 to 67.5 years $) \times 19.2 \%+(N$ age bin 67.5 to 72.5 years $) \times 23.1 \%+(N$ age bin 72.5 to 77.5 years $) \times 27.6 \%+(N$ age bin 77.5 to 82.5 years $) \times 32.6 \%+(N$ age bin 82.5 years and older $) \times 38 \%$

in- and exclusion criteria, which involve absence of disorders that could interfere with trial participation, absence of dementia, and openness to potentially participate in intervention studies and receive disclosure [13]. In three of the cohorts, preselected individuals were then approached by telephone for participation. The population-based cohort GS sent an opt-in letter. In step 3, the EPAD sites performed a telephone screen to check eligibility among those who expressed interest in participating. Prescreen failures during the first 3 steps were categorised as 'matching an exclusion criterion', 'no interest in participation in the study', 'not returning the opt-in letter', 'other reason, not specified' [12]. In step 4, participants visited a site and enrolled in the EPAD-LCS for a screening/baseline visit, after which eligibility was confirmed and amyloid status was determined [13].

\section{Data collected as part of the EPAD-LCS}

From the EPAD-LCS baseline visit, we used clinical information, i.e., the CDR sum of boxes (CDR-SOB) and Mini-Mental State Examination (MMSE); structural MR imaging visual rating scales, i.e., the medial temporal atrophy scale (MTA) mean score and Fazekas deep score of white matter hyperintensities. From the cerebrospinal fluid (CSF) analysis, we used Elecsys A $\beta 1-42$, total tau, and phosphorylated tau values, and from the blood analyses, for some participants, $A P O E$ $\varepsilon 4$ genotype. For a full description of the EPAD-LCS protocols, we refer to [13].

\section{Predictors}

The predictors as collected in the cohorts linked to the Registry were as follows: age, sex, education level (low to normal or high), APOE genotype ( $\varepsilon 4$ noncarrier or carrier), presence of family history for dementia, presence of SCD, and a low score on a delayed recall memory test $(z$-score $<-1.28$, details on definitions of variables Supplement, legend Table 1). All cohorts had data available on demographics. SCD data was present in all cohorts, except GS. APOE genotype was available in the ALFA Study, GS, and a subset of pilotHO.nl. Family history and memory test scores were available for all participants of the ALFA Study and GS, and for the majority in the Toulouse Registry and pilotHO.nl. The definitions of the predictors were as follows: high education was 14 years or more in Toulouse Registry, the ALFA Study, and GS, and in pilotHO.nl a score of 6 or more on the Verhage scale, equivalent to college or university level [19]. Subjective cognitive decline: presence of memory complaints in the absence of impairment on cognitive tests (Toulouse Registry); a positive answer on the question whether the participant memory had complaints (ALFA study), a positive answer on the questions whether the participant memory had complaints and worries about their memory (pilotHO). Low memory delayed recall $z$-score $<-1.28$ on the FCSRT delayed recall (Toulouse), the memory binding test (ALFA study), the Wechsler logical memory - delayed recall (GS), and the Muistikko-test (pilotHO). 


\section{Outcomes}

The first outcome measure was enrolment into the EPAD-LCS, indicating participation in a screening/baseline visit. The second outcome was amyloid positivity, defined as CSF A $\beta 1-42$ below 1098 pg/mL [20-22], for participants who completed and passed the eligibility checks of the EPAD-LCS screening visit.

\section{Statistical analysis}

Participation rate was defined as the percentage of individuals who underwent the EPAD-LCS screening visit out of the individuals approached for participation in the EPAD-LCS. The NNPS was defined as the ratio between the number of individuals contacted for participation and the number of individuals that passed baseline visit classified as amyloid positive. The number needed to screen (NNS) was the ratio between the number of individuals with baseline data and the number of individuals that passed screening visit who were classified as amyloid positive. To test the association between AD risk factors (predictors) and participation into the EPAD-LCS, and among those enrolled, between AD risk factors and amyloid positivity, we applied univariate logistic mixed models with a random term for cohort and fixed term for the predictor. Age was centred at 65. Explorative analyses included analyses stratified now by cohort using univariate logistic regression models. Additionally, as a second step, all significant predictors for either of the two outcomes were combined in two final multivariate models to summarise the results. Statistical analyses were performed in $\mathrm{R}$ version 3.4.2, using packages 'lme4' and 'ImerTest' [23, 24].

\section{Results}

The four cohorts linked to the EPAD Registry included 16,877 participants. The participants were on average $64(\mathrm{SD}=8)$ years old and $39 \%$ were male, and expected amyloid positivity was calculated to be $19 \%$ based on a published meta-analysis [4] (Table 1). Figure 1 and Table 2 describe the recruitment flow of participants to enrolment and amyloid measurement in the EPAD-LCS between May 2016 and March 2018. Table 3 presents clinical, imaging, and CSF markers of the EPAD-LCS baseline visit for participants recruited from each of the cohorts, stratified by amyloid status.

From the EPAD Registry, 3009 individuals were preselected for participation in the EPAD-LCS and 2595 individuals were contacted, of whom 413 (16\%) agreed to participate and were eligible for the EPAD-LCS screening visit. To prevent contacting individuals matching exclusion criteria for the EPADLCS, most cohorts conducted a database check. This was most efficient in the Toulouse registry (100\%). Of the individuals with exclusion criteria in the ALFA Study and in pilotHO.nl, 75\% (110/147) and $55 \%(24 / 53)$ were found during the database check, respectively. Participation rate varied by setting; in the Toulouse Registry, it was 59\%, in the ALFA Study 56\%, in GS 3\%, and in pilotHO.nl 46\%. The primary reasons for not participating were not returning the opt-in leaflet (67\%), no interest (16\%), and other reasons (13\%). Of the 324 participants who had passed the eligibility checks during EPADLCS screening visit and had their amyloid status available, 107 (33\%) participants were amyloid positive. The total number of amyloid-positive individuals was similar between cohorts (Toulouse Registry

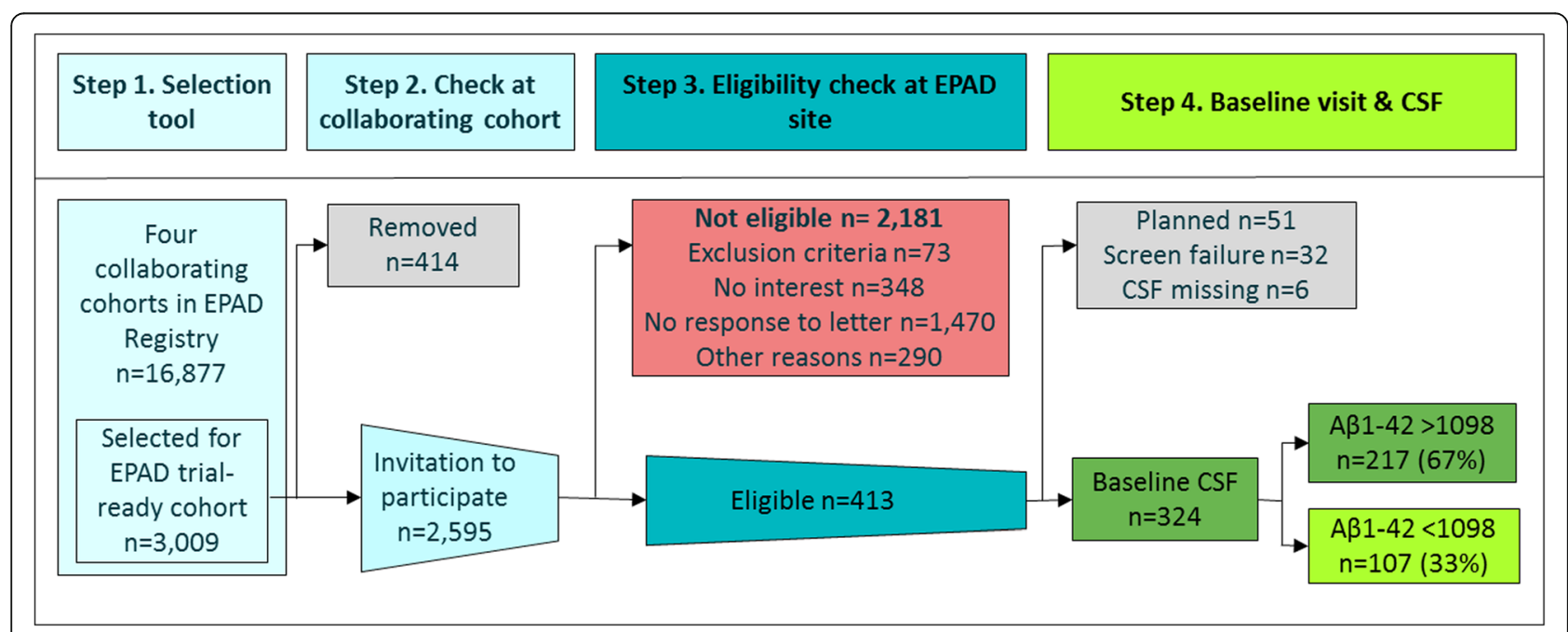

Fig. 1 Prescreening to enrolment: flow from EPAD Registry to EPAD trial-ready cohort. Legend: CSF = cerebrospinal fluid; EPAD = European Prevention of Alzheimer Dementia 
Table 2 Recruitment flow from EPAD Registry by recruitment setting

\begin{tabular}{|c|c|c|c|c|c|c|}
\hline & & Cohorts & & & & Total \\
\hline & & Toulouse Registry & ALFA Study & Generation Scotland & pilotHO.nl & \\
\hline & Setting & Memory clinic & $\begin{array}{l}\text { In-person } \\
\text { research cohort }\end{array}$ & Population-based & Online research cohort & \\
\hline Step 1 & Selection by PREPAD tool & 169 & 618 & 1947 & 275 & 3009 \\
\hline Step 2 & Not eligible based database check & 11 & 347 & 1 & 55 & 414 \\
\hline & - Exclusion criterion & 10 & 110 & 1 & 29 & 150 \\
\hline & - Other & 1 & 237 & 0 & 26 & 264 \\
\hline & $\begin{array}{l}\text { Number selected for step } 3 \\
\text { (\% from step 1) }\end{array}$ & 158 (93\%) & $271(44 \%)$ & $1946(100 \%)$ & $220(80 \%)$ & $2595(86 \%)$ \\
\hline Step 3 & Not eligible after contacting participant & 65 & 119 & 1879 & 119 & 2182 \\
\hline & - No interest & 64 & 24 & 178 & 83 & 349 \\
\hline & - No response to letter & NA & NA & 1470 & NA & 1470 \\
\hline & - Exclusion criterion & 0 & 37 & 12 & 24 & 73 \\
\hline & - Other & 1 & 58 & 219 & 12 & 290 \\
\hline & $\begin{array}{l}\text { Number selected for step } 4 \\
\text { (\% from step 3) }\end{array}$ & $93(59 \%)$ & $152(56 \%)$ & $67(3 \%)$ & $101(46 \%)$ & $413(16 \%)$ \\
\hline Step 4 & EPAD-LCS screening visit & 70 & 137 & 67 & 88 & 362 \\
\hline & Eligible \& CSF A $1-42$ analysed & 64 & 124 & 61 & 75 & 324 \\
\hline & - CSF Aß1-42< 1098 pg/mL (positivity) & $23(36 \%)$ & $36(29 \%)$ & $22(36 \%)$ & $26(35 \%)$ & 107 (33\%) \\
\hline & Number needed to screen & 3.0 & 3.8 & 3.0 & 3.4 & 3.4 \\
\hline & Number needed to prescreen & 6.9 & 7.5 & 88.5 & 8.5 & 24.3 \\
\hline
\end{tabular}

Legend: in italic the total number of the subset on which percentages are based. Number of individuals unless otherwise specified. CSF cerebrospinal fluid, EPADLCS v500 is the currently available data, quality checked at data lock. $N=51$ EPAD screening visit details not yet available. $N=5$ CSF results missing. $N=32$ screen failure: $11 \times$ other disease/incidental findings/CDR $>=1,18 \times$ procedures not possible, $3 \times$ investigator decision/no reason provided/no contact possible. Number needed to screen $=N$ CSF A $1-42$ positive in step $4 / N$ eligible and CSF $A \beta 1-42$ analysed in step 4 , while the number needed to prescreen $=N$ CSF $A \beta 1-42$ positive in step $4 / N$ selected for step 3

$n=23$, ALFA Study $n=36$, GS $n=22$, pilotHO.nl $n=26)$. However, the NNPS to find one eligible amyloid-positive participant varied; in the Toulouse Registry, it was 6.9, in the ALFA Study 7.5, in GS 88.5, and in pilotHO.nl 8.4. Among individuals enrolled in the EPAD-LCS, the NNS in order to find one amyloid- positive individual passing the screening visit was between 3.0 and 3.8 in all settings (Table 2).

\section{Predictors for participation rate}

The AD risk factors that were univariately associated with participation in the EPAD-LCS, for all cohorts

Table 3 Included participants in EPAD Longitudinal cohort study per recruitment setting

\begin{tabular}{|c|c|c|c|c|c|c|c|c|}
\hline & \multicolumn{2}{|c|}{ Toulouse Registry } & \multicolumn{2}{|l|}{ ALFA Study } & \multicolumn{2}{|c|}{ Generation Scotland } & \multicolumn{2}{|l|}{$\underline{\text { pilotHO.nl }}$} \\
\hline & CSF $A \beta+v e$ & CSF A $\beta$ normal & CSF $A \beta+v e$ & CSF A $\beta$ normal & CSF $A \beta+v e$ & CSF A $\beta$ normal & CSF $A \beta+v e$ & CSF A $\beta$ normal \\
\hline$n$ & 23 & 41 & 36 & 88 & 22 & 39 & 26 & 49 \\
\hline Age, year & $71(5)$ & $67(8)^{\wedge}$ & $64(6)$ & $64(5)$ & $71(3)$ & $67(5)^{\#}$ & $68(6)$ & $66(7)$ \\
\hline Male, $n(\%)$ & $4(17 \%)$ & $17(41 \%)$ & $23(64 \%)$ & $41(47 \%)$ & $14(61 \%)$ & $23(57 \%)$ & $14(52 \%)$ & 19 (37\%) \\
\hline MMSE (30-0) & $28.0(2.1)$ & $28.8(1.7)$ & $28.6(1.1)$ & $28.7(1.6)$ & $28.1(1.6)$ & $28.8(1.4)$ & $28.4(1.5)$ & $29.1(1.3)$ \\
\hline CDR-SOB (0-18) & $0.74(0.7)$ & $0.34(0.5)^{\wedge}$ & $0.10(0.3)$ & $0.05(0.2)$ & $0.15(0.3)$ & $0.06(0.2)$ & $0.06(0.2)$ & $0.02(0.1)$ \\
\hline CSF A $1-42, \mathrm{pg} / \mathrm{mL}$ & $756(195)$ & $1613(361)^{\#}$ & $823(191)$ & $1696(519)^{\#}$ & $748(251)$ & $1769(411)^{\#}$ & $846(217)$ & $1788(443)^{\#}$ \\
\hline CSF P-tau, pg/mL & $29(15)$ & $18(4.9)^{\$}$ & $21(15)$ & $17(7)$ & $19(9)$ & $21(12)$ & $21(10)$ & $17(5)$ \\
\hline CSF T-tau, pg/mL & 305 (125) & $210(53)^{\$}$ & $223(132)$ & $209(79)$ & $211(81)$ & $249(115)^{*}$ & $240(101)$ & $206(58)$ \\
\hline MTA (0-4) & $0.4(0.5)$ & $0.2(0.4)$ & $0.2(0.4)$ & $0.1(0.3)$ & $0.4(0.6)$ & $0.1(0.4)$ & $0.2(0.4)$ & $0.2(0.4)$ \\
\hline Fazekas (0-3) & $1.1(0.7)$ & $0.8(0.7)$ & $1(0.6)$ & $0.8(0.6)$ & $1.1(0.9)$ & $0.7(0.7)^{\wedge}$ & $0.9(0.8)$ & $0.9(0.7)$ \\
\hline
\end{tabular}

Legend: MMSE Mini-Mental State Examination, CDR-SOB Clinical Dementia Rating scale- Sum Of Boxes, CSF cerebrospinal fluid, P-tau phosphorylated tau, T-tau total tau, MTA medial temporal lobe atrophy. Mean (SD) unless otherwise specified. ${ }^{*}$ One outlier at t-tau 792 and $\mathrm{p}$-tau 81 . Undetectably low p-tau and t-tau was set at the detection border of 8 and 80 respectively, $\mathrm{A} \beta 1-42$ was extrapolated. Raw $p<0.05={ }^{\wedge} ; p<0.01={ }^{\$}, p<0.001={ }^{\#}$ 
combined, were lower age (odds ratio (OR): age $=0.97$ [0.95-0.99]), high education level $(\mathrm{OR}=1.64$ [1.23$2.17])$, male sex $(\mathrm{OR}=1.56$ [1.19-2.04]), and family history of dementia $(\mathrm{OR}=1.66$ [1.19-2.31], Table 4, for AUCs Additional file 1: Table S2). In single cohorts, participation rates in the Toulouse Registry were predicted by SCD $(\mathrm{OR}=0.29 ;[0.09-0.76])$, in the ALFA Study by male sex $(\mathrm{OR}=2.03[1.24-3.35])$, in GS by male sex $(\mathrm{OR}=1.81[1.11-3.01])$, high education $(\mathrm{OR}=2.20$ [1.34-3.59], and family history $(\mathrm{OR}=2.95$ [1.73-4.91], and in pilotHO.nl by age $(\mathrm{OR}=0.96[0.93-1.00])$. As a next step, we combined the predictor variables age, sex, education, family history, and $A P O E$ in a multivariate model (Fig. 2, Additional file 1: Table S1 and Table S3). Study enrolment was still associated with age, sex, education, and family history ( $n$ with all variables $=2322$ ).

\section{Predictors for amyloid positivity}

Among all individuals enrolled in EPAD-LCS, amyloid positivity was univariately predicted by older age $(\mathrm{OR}=1.06$ [1.02-1.10]) and carrying an $A P O E$ \&4 allele $(\mathrm{OR}=2.99$ [1.81-4.94] $) \quad($ Table 4, for AUCs, Additional file 1: Table S2). In individual cohorts, amyloid positivity in the Toulouse Registry was predicted by higher age $(\mathrm{OR}=1.10[1.01-1.20])$, gender (male $\mathrm{OR}=0.30$ [0.08-0.96]), APOE \&4 $(\mathrm{OR}=6.42$ [1.93-24.1]), and low memory $(\mathrm{OR}=18.90$ [2.87377]; in the ALFA Study by none; in GS by higher age $(\mathrm{OR}=1.23[1.08-1.45])$ and $A P O E \& 4(\mathrm{OR}=7.20$ [2.20-28.77]); and in pilotHO.nl by APOE \&4 (OR = $3.34[1.22-9.48])$. In the multivariate model, including predictor variables age, sex, education, family history, and $A P O E$, amyloid status was predicted by age, $A P O E \varepsilon 4$, and weakly by family history $(p=0.03, n$ with all variables $=322$, Fig. 2 , Additional file 1: Table S1 and Table S3).

\section{Discussion}

Across settings, participation rates varied, while predictors for participation into the trial-ready cohort and amyloid positivity were comparable. Among those contacted for participation, enrolment was higher for individuals who were younger, more educated, or males or had a family history of dementia, while amyloid positivity in the trial-ready cohort was only associated with being older and carrying an $A P O E$ \&4 allele.

The NNPS to find one amyloid-positive eligible participant in the population-based Generation Scotland study was ten times higher than for those cohorts focussed on brain disorders, which may be explained by their willingness to take part in an AD study [25]. Generation Scotland study visits have been completed, and the time between the last Generation Scotland study visit and EPAD recruitment was also longer than for the other cohorts. In addition, an opt-in letter was sent to Generation Scotland participants, while other cohorts contacted individuals by telephone, which may have lowered the response [26]. Moreover, the EPAD study site was at a travel time of $1-3 \mathrm{~h}$ from the recruitment region. Finally, the cohorts from the other settings excluded persons with known exclusion criteria beforehand based on data from their cohort database, which may have decreased later stage prescreen failures. Still, the number of participants recruited of the large

Table 4 Univariate logistic regression for enrolment and CSF A 1-42 positivity in whole sample and stratified by recruitment setting

\begin{tabular}{|c|c|c|c|c|c|c|c|c|c|c|}
\hline \multirow[t]{2}{*}{ Sample size } & \multirow{2}{*}{$\begin{array}{l}\text { Total } \\
n=2595\end{array}$} & \multirow[b]{2}{*}{$n=324$} & \multicolumn{2}{|c|}{ Toulouse Registry } & \multicolumn{2}{|l|}{ ALFA Study } & \multicolumn{2}{|c|}{ Generation Scotland } & \multicolumn{2}{|l|}{ pilotHO.nl } \\
\hline & & & $n=158$ & $n=64$ & $n=271$ & $n=124$ & $n=1947$ & $n=61$ & $n=220$ & $n=75$ \\
\hline Outcome & Enrolment ${ }^{*}$ & $\begin{array}{l}\text { CSFAB } \\
+v e^{\wedge}\end{array}$ & Enrolment ${ }^{*}$ & $\operatorname{CSF} A \beta+v e^{\wedge}$ & Enrolment ${ }^{*}$ & $\begin{array}{l}\operatorname{CSFA\beta } \\
+v e^{\wedge}\end{array}$ & Enrolment ${ }^{*}$ & $\begin{array}{l}\operatorname{CSF} A \beta \\
+v e^{\wedge}\end{array}$ & Enrolment ${ }^{*}$ & $\begin{array}{l}\operatorname{CSFA\beta } \\
+v e^{\wedge}\end{array}$ \\
\hline Aged over 70 years Old & $\begin{array}{l}0.97 \\
(0.95-0.99)\end{array}$ & $\begin{array}{l}1.06 \\
(1.02-1.10)\end{array}$ & $\begin{array}{l}0.99 \\
(0.94-1.03)\end{array}$ & $\begin{array}{l}1.10 \\
(1.01-1.20)\end{array}$ & $\begin{array}{l}0.99 \\
(0.95-1.03)\end{array}$ & $\begin{array}{l}1.01 \\
(0.94-1.08)\end{array}$ & $\begin{array}{l}0.97 \\
(0.93-1.01)\end{array}$ & $\begin{array}{l}1.23 \\
(1.08-1.45)\end{array}$ & $\begin{array}{l}0.96 \\
(0.93-1.00)\end{array}$ & $\begin{array}{l}1.03 \\
(0.97-1.11)\end{array}$ \\
\hline Male & $\begin{array}{l}1.56 \\
(1.19-2.04)\end{array}$ & $\begin{array}{l}1.28 \\
(0.81-2.04)\end{array}$ & $\begin{array}{l}1.17 \\
(0.58-2.42)\end{array}$ & $\begin{array}{l}0.30 \\
(0.08-0.96)\end{array}$ & $\begin{array}{l}2.03 \\
(1.24-3.35)\end{array}$ & $\begin{array}{l}2.03 \\
(0.92-4.60)\end{array}$ & $\begin{array}{l}1.81 \\
(1.11-3.01)\end{array}$ & $\begin{array}{l}1.35 \\
(0.47-4.08)\end{array}$ & $\begin{array}{l}1.13 \\
(0.66-1.94)\end{array}$ & $\begin{array}{l}2.01 \\
(0.77-5.36)\end{array}$ \\
\hline Highly & $\begin{array}{l}1.64 \\
(1.23-2.17)\end{array}$ & $\begin{array}{l}0.89 \\
(0.56-1.42)\end{array}$ & $\begin{array}{l}1.44 \\
(0.69-2.98)\end{array}$ & $\begin{array}{l}0.72 \\
(0.25-2.13)\end{array}$ & $\begin{array}{l}1.42 \\
(0.87-2.31)\end{array}$ & $\begin{array}{l}1.10 \\
(0.50-2.39)\end{array}$ & $\begin{array}{l}2.20 \\
(1.34-3.59)\end{array}$ & $\begin{array}{l}0.66 \\
(0.22-1.88)\end{array}$ & $\begin{array}{l}1.33 \\
(0.67-2.67)\end{array}$ & $\begin{array}{l}0.75 \\
(0.24-2.51)\end{array}$ \\
\hline APOE $\varepsilon 4$ genotype & $\begin{array}{l}0.95 \\
(0.70-1.28)\end{array}$ & $\begin{array}{l}2.99 \\
(1.81-4.94)\end{array}$ & NA & $\begin{array}{l}6.42 \\
(1.93-24.1)\end{array}$ & $\begin{array}{l}0.68 \\
(0.41-1.10)\end{array}$ & $\begin{array}{l}1.72 \\
(0.79-3.86)\end{array}$ & $\begin{array}{l}1.37 \\
(0.84-2.25)\end{array}$ & $\begin{array}{l}7.20 \\
(2.2-28.77)\end{array}$ & $\begin{array}{l}0.92 \\
(0.49-1.72)\end{array}$ & $\begin{array}{l}3.34 \\
(1.22-9.48)\end{array}$ \\
\hline $\begin{array}{l}\text { Family history of } \\
\text { Dementia }\end{array}$ & $\begin{array}{l}1.66 \\
(1.19-2.31)\end{array}$ & $\begin{array}{l}1.58 \\
(0.83-3.00)\end{array}$ & $\begin{array}{l}1.04 \\
(0.50-2.15)\end{array}$ & $\begin{array}{l}0.95 \\
(0.31-2.98)\end{array}$ & $\begin{array}{l}1.12 \\
(0.38-3.23)\end{array}$ & $N A^{\#}$ & $\begin{array}{l}2.95 \\
(1.73-4.91)\end{array}$ & $\begin{array}{l}2.90 \\
(0.97-8.96)\end{array}$ & $\begin{array}{l}1.27 \\
(0.73-2.22)\end{array}$ & $\begin{array}{l}1.94 \\
(0.68-6.09)\end{array}$ \\
\hline $\begin{array}{l}\text { Subjective cognitive } \\
\text { decline }\end{array}$ & $\begin{array}{l}0.86 \\
(0.58-1.27)\end{array}$ & $\begin{array}{l}1.51 \\
(0.88-2.61)\end{array}$ & $\begin{array}{l}0.29 \\
(0.09-0.76)\end{array}$ & $\begin{array}{l}2.93 \\
(0.67-20.6)\end{array}$ & $\begin{array}{l}0.79 \\
(0.41-1.55)\end{array}$ & $\begin{array}{l}1.15 \\
(0.38-3.22)\end{array}$ & NA & NA & $\begin{array}{l}1.16 \\
(0.62-2.15)\end{array}$ & $\begin{array}{l}1.73 \\
(0.62-4.79)\end{array}$ \\
\hline Low memory score & $\begin{array}{l}0.84 \\
(0.60-1.17)\end{array}$ & $\begin{array}{l}1.47 \\
(0.82-2.61)\end{array}$ & $\begin{array}{l}0.63 \\
(0.21-1.87)\end{array}$ & $\begin{array}{l}18.90(2.87- \\
377)\end{array}$ & $\begin{array}{l}0.95 \\
(0.56-1.64)\end{array}$ & $\begin{array}{l}1.29 \\
(0.55-2.96)\end{array}$ & $\begin{array}{l}0.78 \\
(0.44-1.31)\end{array}$ & $\begin{array}{l}0.95 \\
(0.28-3.02)\end{array}$ & $\begin{array}{l}0.91 \\
(0.29-2.83)\end{array}$ & $\begin{array}{l}0.58 \\
(0.03-4.98)\end{array}$ \\
\hline
\end{tabular}

Odds ratio $(95 \% \mathrm{Cl})$; CSF cerebrospinal fluid. Italics is significant $p<0.05$. ${ }^{*}$ Odds ratio for participating baseline/screening visit after invitation. $\wedge$ Odds ratio for amyloid positivity among those included in EPAD-LCS. "Infinite, not possible to calculate a value 

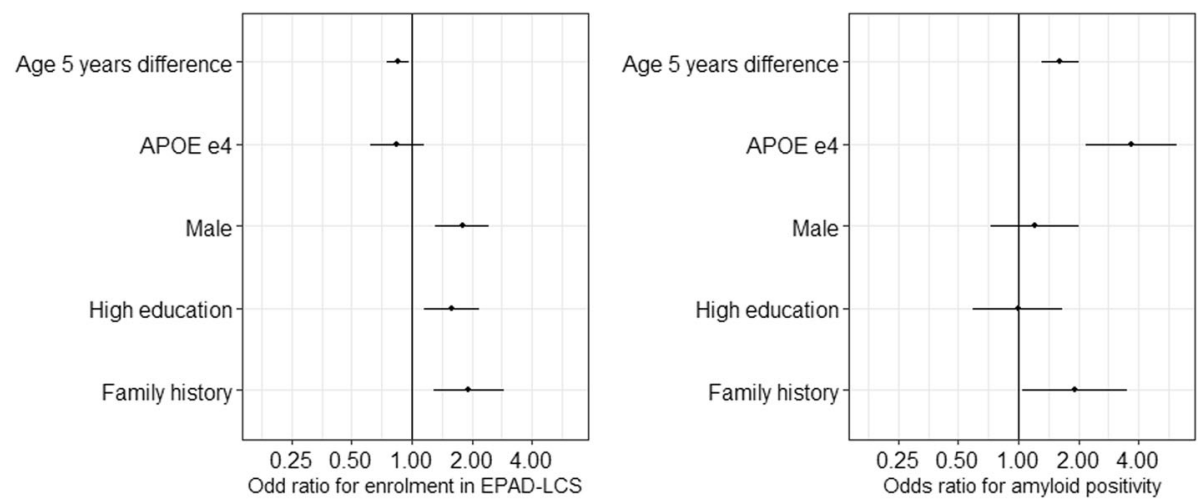

Fig. 2 Multivariate model for enrolment and amyloid positivity. Legend: EPAD-LCS = EPAD longitudinal cohort study (trial-ready cohort). APOE = apolipoprotein E gene. Shown effect sizes are: Age per 5 years older at baseline, APOE $\varepsilon 4$ in contrast to no APOE $\varepsilon 4$, male in contrast to female, highly educated in contrast to low or normal level educated, family history for dementia positive in contrast to family history for dementia reported

population-based Generation Scotland cohort was comparable to the bespoke cohorts, suggesting that there is scope and willingness within these types of cohorts to participate in dementia-related intervention studies.

Lower participation at older ages and higher participation for both highly educated participants and those with a family history of dementia are in line with studies with dementia patients and online registers [9, 10, 27-29]. Barriers for older individuals to participate may include morbidities, difficulties to travel, and not having a study partner. The higher participation rate of males was unexpected, as many research studies have lower male than female participation $[9,10,30,31]$.

The predictors for amyloid positivity, i.e. age and $A P O E$, were as expected and in line with previous studies, including an EPAD-LCS full dataset analysis $[4,6,32,33]$. Low memory scores, in contrast, were only a significant predictor for amyloid positivity in the memory clinic cohort and the presence of SCD did not predict amyloid positivity in our sample. As low memory scores were the best predictor for amyloid positivity in the memory clinic setting, memory tests may form a useful prescreen in this situation. An explanation for the discrepancy with previously reported associations of these factors with amyloid status could be the non-standardised test data and could possibly show better predictive effects with the use of tailored sensitive tests and questionnaires [9, 11, 32, 34-37].

The prevalence of amyloid positivity in those enrolled in the EPAD-LCS was 33\%. This prevalence was enriched around 1.5 times compared to the estimated prevalence in the whole cohorts based on a metaanalysis of prevalence in cognitively normal individuals [4]. The limited increase in prevalence of amyloid positivity could be explained by the fact that the variables available for prescreening each have a modest predictive accuracy for amyloid positivity [4, 6]. Another explanation is that low- and intermediate-risk individuals were selected from the cohorts in order to prevent risk disclosure by invitation and to have sufficient enrolment in the EPAD-LCS.

An advantage of our approach compared to other recruitment strategies such as media campaign advertisement is that the use of existing data helped to exclude individuals with known exclusion criteria for secondary prevention trials. However, no direct comparison of efficiency relative to other prescreening strategies (e.g. advertising) could be made. A disadvantage of our approach is that consent to re-contact needs to be present in the cohorts and some costs are involved in the prescreening. In addition, cohorts become depleted, as shown for the smaller cohorts in our study. Future projects could involve direct comparisons between recruitment strategies and focus on cost and effort monitoring and comparison. Another important factor when recruiting from collaborating studies, as well as in the gathering of a 'trial-ready cohort' is the aspect of time and cohort maintenance costs of both the recruitment cohorts and EPAD-LCS, but substantial. As AD is a progressive disorder, the time between testing in a parent cohort and time of selection may be important. Future work on the EPAD-LCS and similar projects needs to optimise the costs and efforts of maintaining a trial ready cohort. This should also involve monitoring the rate at which individuals become ineligible over time, for example because they develop comorbidities that are exclusion criteria.

A limitation is that the analyses were done with the risk factors available in each cohort, such that not all risk factors were available in all cohorts for all individuals. Also, the use of the available data and adaptation to 
local standard procedures meant that there was variability in the operationalisation of variables. Secondly, algorithms for preselection in the EPAD Registry tool included predictor variables of the current study. Still, that is unlikely to influence the association between each of the risk factors and participation rate as multivariate models yielded similar results. Additionally, cohorts were different from each other in more than one factor, such as sample size, population characteristics, and communication style. Therefore, differences in recruitment rate may be explained by several factors. Despite the differences, participation rate was associated with similar $A D$ risk factors across cohorts. Finally, we have now studied the participation in a trial-ready cohort, but enrolment into an actual clinical trial might give different results, depending on study-specific in- and exclusion criteria and trial design [38]. Strengths of our study are the prospective prescreening and the large sample in which amyloid-testing was performed.

Our comparison of common AD risk factors for their association with participation rate and amyloid positivity has several implications for prescreening strategies for secondary prevention trials aimed at individuals with amyloid pathology. Age was a relatively strong predictor for amyloid positivity. However, we also showed that elderly individuals were less likely to participate in the study, which would limit the prescreening efficiency of age for amyloid positivity. Therefore, addressing barriers for older individuals to participate could increase recruitment of eligible participants [29, 39]. Carrying an $A P O E$ \&4 allele was also a strong predictor of amyloid status, but as published before, the disadvantage is that around $40 \%$ of amyloid-positive individuals are $A P O E \& 4$ non-carriers [40]. The prevalence of $A P O E \& 4$ positivity is around $20-30 \%$ and this may therefore not be optimal for prescreening in a small cohort. Disclosure of genotype could also be an issue $[10,41]$. These limitations may be overcome by using a family history for dementia as a prescreener. The advantage of this risk factor is the association with a greater enrolment rate, but the disadvantage is that its association with amyloid positivity is weak and the prevalence in the general population low. Subtle memory decline or concerns were not a useful prescreen for amyloid status in our study, but more specific tests or questionnaires may perform better [11, $42,43]$. A promising alternative may be blood tests for amyloid [5, 44, 45]. With a sensitive threshold, such a test has the advantage to more effectively prescreen relatively younger individuals, who often comprise a large part of a registry population and are more likely to participate, but have a low prevalence of amyloid pathology.

\section{Conclusions}

We found that enrolment rates show major differences between cohorts, although predictors for participation were similar. The provided NNPS to find one eligible amyloid-positive participant are indicators that future recruitment strategies can relate to. The findings highlight considerations of clinical trial investigators, balancing a gain in the ease of recruitment with potentially reducing the generalizability of the trial. Measures to increase efficiency for recruitment for secondary prevention trials may include using prospective registries with continuous enrolment of participants, adding a prescreening step with sensitive measures, such as a blood test, and addressing barriers for older and lower-educated individuals to participate.

\section{Supplementary information}

The online version of this article (https://doi.org/10.1186/s13195-019-0576-y) contains supplementary material, which is available to authorized users.

Additional file 1: Table S1. Multivariate logistic regression for enrolment and CSF A $1-42$ positivity in whole sample. Table S2. AUC for binominal ROC curves of Table 4. Table S3. AUC on multivariate model Fig. 2. (DOCX 23 kb)

\section{Abbreviations \\ AD: Alzheimer disease; APOE: Apolipoprotein E; CDR-SOB: Clinical Dementia Rating Scale Sum of Boxes; EPAD: European Prevention of Alzheimer Dementia; EPAD-LCS: EPAD longitudinal cohort study; GS: Generation Scotland; MMSE: Mini-Mental State Examination; MTA: Medial temporal lobe atrophy; NNPS: Number needed to prescreen; NNS: Number needed to screen; P-tau: Phosphorylated tau; SCD: Subjective cognitive decline; T- tau: Total tau}

\section{Acknowledgements}

All studies are grateful to all research participants and patients who took part in any of the cohorts and the professionals involved in conducting the studies, which includes medical doctors, interviewers, computer and laboratory technicians, clerical workers, research scientists, volunteers, managers, receptionists, healthcare assistants, and nurses. We also specifically thank EPAD colleagues involved in the EPAD Registry, especially Carlos Diaz, Sandra Pla, Iva Knezevic, and Harry Peaker.

\section{Authors' contributions}

LV contributed to the concept and design, data collection, statistical analysis, and writing of the manuscript. GM-T contributed to the concept and design, statistical analysis, revision of the manuscript, and supervision. LtM contributed to the data collection and revision of the manuscript. CV contributed to the data collection and revision of the manuscript. KB contributed to the

data collection and revision of the manuscript. AC contributed to the access to cohort participants and data and revision of the manuscript. JD contributed to the access to cohort participants and data, data collection, and revision of the manuscript. IC contributed to the access to cohort participants and data, data collection, and revision of the manuscript. KF contributed to the access to cohort participants and data, data collection, and revision of the manuscript. SI contributed to the data collection and revision of the manuscript. NJ contributed to the data collection and revision of the manuscript. JLM contributed to the obtained funding, access to cohort participants and data, data collection, and revision of the manuscript. P-JO obtained funding and contributed to the access to cohort participants and data, data collection, and revision of the manuscript. DP contributed to the access to cohort participants and data and revision of the manuscript. NDP contributed to the access to cohort participants and data and revision of the manuscript. AS obtained funding and contributed to the data collection and revision of the manuscript. BT contributed to the data collection and revision 
of the manuscript. $\mathrm{HZ}$ contributed to the data collection and revision of the manuscript. MZ contributed to the access to cohort participants and data and revision of the manuscript. CR obtained funding and contributed to the data collection and revision of the manuscript. PS obtained funding and contributed to the data collection and revision of the manuscript. GL obtained funding and contributed to the data collection and revision of the manuscript. AJB obtained funding and contributed to the data collection and revision of the manuscript. PJV obtained funding and contributed to the concept and design, data collection, statistical analysis, writing manuscript, and supervision. All authors read and approved the final manuscript.

\section{Funding}

The research leading to these results has received support from the Innovative Medicines Initiative Joint Undertaking under grant agreement $n^{\circ} 115736$, resources of which are composed of financial contribution from the European Union's Seventh Framework Programme (FP7/2007-2013) and EFPIA companies' in kind contribution. Generation Scotland received core support from the Chief Scientist Office of the Scottish Government Health Directorates [CZD/16/6] and the Scottish Funding Council [HR03006]. Genotyping was carried out by the Genetics Core Laboratory at the Wellcome Trust Clinical Research Facility, Edinburgh, Scotland and was funded by the Medical Research Council UK and the Wellcome Trust (Reference 104036/Z/14/Z).

\section{Availability of data and materials}

The EPAD data used in this analysis will be made available on an openaccess platform in due course. (www.ep-ad.org for updates).

\section{Ethics approval and consent to participate}

The EPAD-LCS (www.clinicaltrials.gov: NCT02804789) and the other cohorts were approved by the ethical review board in each country in which the study was performed, and all participants gave informed consent. The cohort studies had consent to contact participants for other research projects.

\section{Consent for publication}

Not applicable.

\section{Competing interests}

Lisa Vermunt, Graciela Muniz-Terrera, Lea ter Meulen, Colin Veal, Archie Campbell, Julien Delrieu, Isabelle Carrie, Karine Fauria, Silvia Ingala, Natalie Jenkins, Pierre-Jean Ousset, David Porteous, Alina Solomon, Brian Tom, Marissa Zwan, and Anthony Brookes declare that they have no competing interests.

Kaj Blennow has served as a consultant or at advisory boards for Alector, Alzheon, CogRx, Biogen, Lilly, Novartis, and Roche Diagnostics, has received research support from Roche Diagnostics, and is a co-founder of Brain Biomarker Solutions in Gothenburg AB, a GU Venture-based platform company at the University of Gothenburg. José Luis Molinuevo is a consultant for the following for-profit companies: Alergan, Roche diagnostics, Genentech, Novartis, Lundbeck, Oryzon, Biogen, Lilly, Janssen, Green Valley, MSD, Eisai, Alector, Raman Health. Niels Prins serves on the advisory board of Boehringer Ingelheim and Probiodrug and is a member of the DSMB of Abbvie's M15566 trial; he has received consultancy or speaker fees from Sanofi, Takeda, Janssen, and Novartis and he is CEO and co-owner of the Brain Research Center, Amsterdam. Henrik Zetterberg has served at scientific advisory boards for Roche Diagnostics, Wave, Samumed, and CogRx, has given lectures in symposia sponsored by Biogen and Alzecure, and is a co-founder of Brain Biomarker Solutions in Gothenburg AB, a GU Ventures-based platform company at the University of Gothenburg. Craig Ritchie is the co-coordinator and academic lead for the EPAD (European Prevention of Alzheimer's Dementia) Project which has numerous commercial partners in keeping with the mechanisms of the European Union's Innovative Medicine's Initiative. These companies are as follows: Janssen, Eisai, Pfizer, Eli Lilly, Roche Diagnostics, Boeringher Ingleheim, Novartis, AC Immune, Ixico, Aridhia, Amgen, Berry Consultants, Lundbeck, Sanofi, Quintiles (IQVIA), and Takeda. Philip Scheltens has acquired grant support (for the institution) from GE Healthcare, Danone Research, Piramal, and Merck. In the past 2 years, he has received consultancy/speaker fees (paid to the institution) from Lilly, GE Healthcare, Novartis, Sanofi, Nutricia, Probiodrug, Biogen, Roche, Avraham, and EIP Pharma. Gerald Luscan is a Pfizer employee. Pieter Jelle Visser reports non-financial support from GE Healthcare, other from Eli-Lilly, other from Janssen Pharmaceutical, grants from Biogen, outside the submitted work.

\section{Author details}

'Department of Neurology, Alzheimer Center Amsterdam, Amsterdam Neuroscience, Amsterdam UMC, Vrije Universiteit, PO Box 7057, 1007 MB Amsterdam, The Netherlands. ${ }^{2}$ Centre for Dementia Prevention, University of Edinburgh, Edinburgh, Scotland. ${ }^{3}$ Department of Genetics, University of Leicester, Leicester, UK. ${ }^{4}$ Department of Psychiatry and Neurochemistry, Institute of Neuroscience and Physiology, the Sahlgrenska Academy at the University of Gothenburg, Mölndal, Sweden. ${ }^{5}$ Clinical Neurochemistry Laboratory, Sahlgrenska University Hospital, Mölndal, Sweden. ${ }^{6}$ Molecular Medicine Centre, Institute of Genetics and Molecular Medicine, University of Edinburgh, Edinburgh, UK. ${ }^{7}$ Centre de Recherche Clinique du Gérontopôle, Toulouse University Hospital, Toulouse, France. ${ }^{8}$ Gérontopôle de Toulouse, UMR INSERM 1027, Toulouse University Hospital, Toulouse, France. ${ }^{9}$ BarcelonaBeta Brain Research Center, Fundacio Pasqual Maragall, Barcelona, Spain. ${ }^{10}$ Department of Radiology and Nuclear Medicine, Amsterdam Neuroscience, Amsterdam UMC, Vrije Universiteit, Amsterdam, The Netherlands. "Brain Research Center, Amsterdam, The Netherlands.

${ }^{12}$ Institute of Clinical Medicine, Neurology, University of Eastern Finland, P.O. Box 1627, 70211 Kuopio, Finland. ${ }^{13}$ Division of Clinical Geriatrics, NVS, Karolinska Institutet, Stockholm, Sweden. ${ }^{14}$ MRC Biostatistics Unit, University of Cambridge, Cambridge, UK. ${ }^{15}$ Department of Neurodegenerative Disease, UCL Institute of Neurology, London, UK. ${ }^{16}$ UK Dementia Research Institute at UCL, London, UK. ${ }^{17}$ Global Innovative Pharma Business - Clinical Sciences, Pfizer, Paris, France. ${ }^{18}$ Department of Psychiatry and Neuropsychology, School for Mental Health and Neuroscience (MHeNS), Alzheimer Centrum Limburg, Maastricht University, Maastricht, The Netherlands.

Received: 13 July 2019 Accepted: 23 December 2019

Published online: 06 January 2020

\section{References}

1. Aisen P, Touchon J, Andrieu S, Boada M, Doody R, Nosheny R. Registries and cohorts to accelerate early phase Alzheimer's trials. A report from the EU/US Clinical Trials in Alzheimer's Disease Task Force. J Prev Alz Dis. 2016;3:68-74.

2. Fargo KN, Carrillo MC, Weiner MW, Potter WZ, Khachaturian Z. The crisis in recruitment for clinical trials in Alzheimer's and dementia: an action plan for solutions. Alzheimers Dement. 2016;12(11):1113-5.

3. Sperling RA, Aisen PS, Beckett LA, Bennett DA, Craft S, Fagan AM, Iwatsubo T, Jack CR Jr, Kaye J, Montine TJ, et al. Toward defining the preclinical stages of Alzheimer's disease: recommendations from the National Institute on Aging-Alzheimer's Association workgroups on diagnostic guidelines for Alzheimer's disease. Alzheimers Dement. 2011;7(3):280-92.

4. Jansen WJ, Ossenkoppele R, Knol DL, Tijms BM, Scheltens P, Verhey FR, Visser PJ, Amyloid Biomarker Study G, Aalten P, Aarsland D, et al. Prevalence of cerebral amyloid pathology in persons without dementia: a metaanalysis. JAMA. 2015;313(19):1924-38.

5. Verberk IMW, Slot RE, Verfaillie SCJ, Heijst H, Prins ND, van Berckel BNM, Scheltens P, Teunissen CE, van der Flier WM. Plasma amyloid as prescreener for the earliest Alzheimer pathological changes. Ann Neurol. 2018;84(5):648-58.

6. Insel PS, Palmqvist S, Mackin RS, Nosheny RL, Hansson O, Weiner MW, Mattsson N. Assessing risk for preclinical beta-amyloid pathology with APOE, cognitive, and demographic information. Alzheimers Dement (Amst). 2016;4:76-84.

7. Grill JD. Recruiting to preclinical Alzheimer's disease clinical trials through registries. Alzheimers Dement (N Y). 2017;3(2):205-12.

8. Boada M, Santos-Santos MA, Rodriguez-Gomez O, Alegret M, Canabate P. Lafuente A, Abdelnour C, Buendia M, de Dios MJ, Morera A, et al. Patient engagement: the Fundacio ACE framework for improving recruitment and retention in Alzheimer's disease research. J Alzheimers Dis. 2018;62(3):1079-90.

9. Weiner MW, Nosheny R, Camacho M, Truran-Sacrey D, Mackin RS, Flenniken D, Ulbricht A, Insel P, Finley S, Fockler J, et al. The Brain Health Registry: an internet-based platform for recruitment, assessment, and longitudinal monitoring of participants for neuroscience studies. Alzheimers Dement. 2018;14(8):1063-76.

10. Langbaum JB, Karlawish J, Roberts JS, Wood EM, Bradbury A, High N, Walsh TL, Gordon D, Aggarwal R, Davis P, et al. GeneMatch: a novel recruitment registry using at-home APOE genotyping to enhance referrals to Alzheimer's prevention studies. Alzheimers Dement. 2019;15(4):515-24. 
11. Lim YY, Yassi N, Bransby L, Properzi M, Buckley R. The healthy brain project: an online platform for the recruitment, assessment, and monitoring of middleaged adults at risk of developing Alzheimer's disease. J Alzheimers Dis. 2019; 68(3):1211-1228

12. Vermunt $L$, Veal CD, Ter Meulen $L$, Chrysostomou C, van der Flier W, Frisoni GB, Guessous I, Kivipelto M, Marizzoni M, Martinez-Lage P, et al. European Prevention of Alzheimer's Dementia Registry: recruitment and prescreening approach for a longitudinal cohort and prevention trials. Alzheimers Dement. 2018;14(6):837-42.

13. Solomon A, Kivipelto M, Molinuevo JL, Tom B, Ritchie CW, Consortium E. European Prevention of Alzheimer's Dementia Longitudinal Cohort Study (EPAD LCS): study protocol. BMJ Open. 2019;8(12):e021017.

14. Ritchie CW, Molinuevo JL, Truyen L, Satlin A, Van der Geyten S, Lovestone S, European Prevention of Alzheimer's Dementia C. Development of interventions for the secondary prevention of Alzheimer's dementia: the European prevention of Alzheimer's dementia (EPAD) project. Lancet Psychiatry. 2016;3(2):179-86.

15. Vellas B, Aisen PS, Sampaio C, Carrillo M, Scheltens P, Scherrer B, Frisoni GB, Weiner M, Schneider L, Gauthier S, et al. Prevention trials in Alzheimer's disease: an EU-US task force report. Prog Neurobiol. 2011;95(4):594-600.

16. Molinuevo JL, Gramunt N, Gispert JD, Fauria K, Esteller M, Minguillon C, Sánchez-Benavides G, Huesa G, Morán S, Dal-Ré R, et al. The ALFA project: a research platform to identify early pathophysiological features of Alzheimer's disease. Alzheimers Dement. 2016;2(2):82-92

17. Smith BH, Campbell A, Linksted P, Fitzpatrick B, Jackson C, Kerr SM, Deary IJ, Macintyre DJ, Campbell H, McGilchrist M, et al. Cohort profile: generation Scotland: Scottish family health study (GS:SFHS). The study, its participants and their potential for genetic research on health and illness. Int J Epidemiol. 2013;42(3):689-700.

18. Lancaster O, Beck T, Atlan D, Swertz M, Thangavelu D, Veal C, Dalgleish R, Brookes AJ. Cafe Variome: general-purpose software for making genotypephenotype data discoverable in restricted or open access contexts. Hum Mutat. 2015;36(10):957-64.

19. Verhage F. Intelligentie en Leeftijd: Onderzoek bij Nederlanders van Twaalf tot Zevenzeventig Jaar [Intelligence and Age: Study with Dutch People Aged 12 to 77]. Assen: Van Gorcum; 1964.

20. Shaw LM, Waligorska T, Fields L, Korecka M, Figurski M, Trojanowski JQ, Eichenlaub U, Wahl S, Quan M, Pontecorvo MJ, et al. Derivation of cutoffs for the Elecsys((R)) amyloid beta (1-42) assay in Alzheimer's disease. Alzheimers Dement (Amst). 2018:10:698-705.

21. Schindler SE, Sutphen CL, Teunissen C, McCue LM, Morris JC, Holtzman DM, Mulder SD, Scheltens P, Xiong C, Fagan AM. Upward drift in cerebrospinal fluid amyloid beta 42 assay values for more than 10 years. Alzheimers Dement. 2018;14(1):62-70.

22. Hansson O, Seibyl J, Stomrud E, Zetterberg H, Trojanowski JQ, Bittner T, Lifke V, Corradini V, Eichenlaub U, Batrla R, et al. CSF biomarkers of Alzheimer's disease concord with amyloid-beta PET and predict clinical progression: a study of fully automated immunoassays in BioFINDER and ADNI cohorts. Alzheimers Dement. 2018;14(11):1470-1481.

23. R: A Language and Environment for Statistical Computing [https://www.Rproject.org]. Accessed 29 May 2019

24. Ime4: Linear mixed-effects models using Eigen and S4 [http://CRAN.Rproject.org/package=Ime4]. Accessed 29 May 2019.

25. Barber JM, Bardach SH, Jicha GA. Alzheimer disease clinical trial recruitment: does participation in a brief cognitive screen at a community health fair promote research engagement? Alzheimer Dis Assoc Disord. 2018;32(4):333-8.

26. Gul RB, Ali PA. Clinical trials: the challenge of recruitment and retention of participants. J Clin Nurs. 2010;19(1-2):227-33

27. James SN, Lane CA, Parker TD, Lu K, Collins JD, Murray-Smith H, Byford M, Wong A, Keshavan A, Buchanan S, et al. Using a birth cohort to study brain health and preclinical dementia: recruitment and participation rates in insight 46. BMC Res Notes. 2018;11(1):885.

28. Schoenmaker N, Van Gool WA. The age gap between patients in clinical studies and in the general population: a pitfall for dementia research. Lancet Neurol. 2004;3(10):627-30.

29. Grill JD, Galvin JE. Facilitating Alzheimer disease research recruitment. Alzheimer Dis Assoc Disord. 2014;28(1):1-8.

30. Abdelnour C, Rodriguez-Gomez O, Alegret M, Valero S, Moreno-Grau S, Sanabria A, Hernandez I, Rosende-Roca M, Vargas L, Mauleon A, et al.
Impact of recruitment methods in subjective cognitive decline. J Alzheimers Dis. 2017:57(2):625-32

31. Honig LS, Vellas B, Woodward M, Boada M, Bullock R, Borrie M, Hager K, Andreasen N, Scarpini E, Liu-Seifert H, et al. Trial of Solanezumab for mild dementia due to Alzheimer's disease. N Engl J Med. 2018;378(4):321-30.

32. Wolfsgruber S, Molinuevo JL, Wagner M, Teunissen CE, Rami L, Coll-Padros $\mathrm{N}$, Bouwman FH, Slot RER, Wesselman LMP, Peters O, et al. Prevalence of abnormal Alzheimer's disease biomarkers in patients with subjective cognitive decline: cross-sectional comparison of three European memory clinic samples. Alzheimers Res Ther. 2019;11(1):8.

33. Ritchie CW M-TG, Kivipelto M, Solomon Alina, Tom B and Molinuevo JL: The European Prevention of Alzheimer's Dementia (EPAD) Longitudinal Cohort Study: Data Release V500.0 2019, in press.

34. Jansen WJ, Ossenkoppele R, Tijms BM, Fagan AM, Hansson O, Klunk WE, van der Flier WM, Villemagne VL, Frisoni GB, Fleisher AS, et al. Association of cerebral amyloid-beta aggregation with cognitive functioning in persons without dementia. JAMA Psychiatry. 2018;75(1):84-95.

35. Fladby $T$, Palhaugen $L$, Selnes P, Waterloo K, Brathen G, Hessen E, Almdahl IS, Arntzen KA, Auning E, Eliassen CF, et al. Detecting at-risk Alzheimer's disease cases. J Alzheimers Dis. 2017:60(1):97-105.

36. Palmqvist $\mathrm{S}$, Insel PS, Zetterberg H, Blennow K, Brix B, Stomrud E, Alzheimer's Disease Neuroimaging I, Swedish Bio Fs, Mattsson N, Hansson $\mathrm{O}$. Accurate risk estimation of beta-amyloid positivity to identify prodromal Alzheimer's disease: cross-validation study of practical algorithms. Alzheimers Dement. 2019;15(2):194-204.

37. Baker JE, Lim YY, Pietrzak RH, Hassenstab J, Snyder PJ, Masters CL, Maruff P. Cognitive impairment and decline in cognitively normal older adults with high amyloid-beta: a meta-analysis. Alzheimers Dement (Amst). 2017;6:108-21.

38. Nuno MM, Gillen DL, Dosanjh KK, Brook J, Elashoff D, Ringman JM, Grill JD. Attitudes toward clinical trials across the Alzheimer's disease spectrum. Alzheimers Res Ther. 2017;9(1):81.

39. Largent EA, Karlawish J, Grill JD. Study partners: essential collaborators in discovering treatments for Alzheimer's disease. Alzheimers Res Ther. 2018; 10(1):101.

40. Mattsson N, Groot C, Jansen WJ, Landau SM, Villemagne VL, Engelborghs S, Mintun MM, Lleo A, Molinuevo JL, Jagust WJ, et al. Prevalence of the apolipoprotein E epsilon4 allele in amyloid beta positive subjects across the spectrum of Alzheimer's disease. Alzheimers Dement. 2018;14(7):913-24.

41. Green RC, Roberts JS, Cupples LA, Relkin NR, Whitehouse PJ, Brown T. Disclosure of APOE genotype for risk of Alzheimer's disease. N Engl J Med. 2009:361(3):245-54

42. Molinuevo JL, Rabin LA, Amariglio R, Buckley R, Dubois B, Ellis KA, Ewers M, Hampel H, Kloppel S, Rami L, et al. Implementation of subjective cognitive decline criteria in research studies. Alzheimers Dement. 2017;13(3):296-311.

43. Donohue MC, Sperling RA, Salmon DP, Rentz DM, Raman R, Thomas RG, Weiner M, Aisen PS, Australian Imaging B, Lifestyle Flagship Study of A, et al. The preclinical Alzheimer cognitive composite: measuring amyloid-related decline. JAMA Neurol. 2014:71(8):961-70.

44. Nakamura A, Kaneko N, Villemagne VL, Kato T, Doecke J, Dore V, Fowler C, Li QX, Martins R, Rowe C, et al. High performance plasma amyloid-beta biomarkers for Alzheimer's disease. Nature. 2018;554(7691):249-54.

45. Janelidze $S$, Stomrud E, Palmqvist $S$, Zetterberg H, van Westen D, Jeromin A, Song L, Hanlon D, Tan Hehir CA, Baker D, et al. Plasma beta-amyloid in Alzheimer's disease and vascular disease. Sci Rep. 2016;6:26801.

\section{Publisher's Note}

Springer Nature remains neutral with regard to jurisdictional claims in published maps and institutional affiliations. 